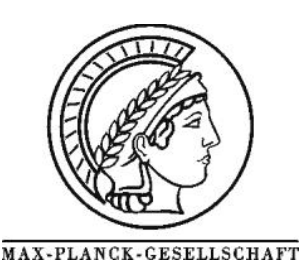

\title{
Preparation, Characterization and Catalytic Testing of GePt Catalysts
}

\author{
N. Győrffy ${ }^{a}$, I. Bakos ${ }^{b}$, S. Szabó ${ }^{b}$, L .Tóth ${ }^{c}$, U. Wild ${ }^{d}$, R. Schlögl ${ }^{d}$, Z. Paál ${ }^{a *}$
}

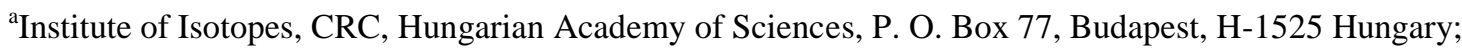

${ }^{\mathrm{b}}$ Institute of Material and Environmental Chemistry, CRC, HAS, POB. 17, Budapest, H-1525, Hungary

${ }^{c}$ Institute of Technical Physics and Materials Science, Hungarian Academy of Sciences, P. O. Box 49, Budapest,

H-1525 Hungary;

${ }^{\mathrm{d}}$ Fritz-Haber-Institut der MPG, Faradayweg 4-6, D-14195 Berlin, Germany.

*Corresponding author: e-mail paal@iki.kfki.hu,

Received 28 October 2008, Revised 26 February 2009, Accepted 28 February 2009, Available online 20 March 2009

\begin{abstract}
Unsupported and $\mathrm{SiO}_{2}$ supported GePt bimetallic catalysts were prepared by depositing Ge on to Pt underpotentially. Surface-sensitive cyclic voltammetry of Pt black indicated that Ge covered ca. 40-45\% of the Pt surface, whereas XPS showed just $\sim 96 \% \mathrm{Pt}$ and $\sim 4 \%$ Ge (normalized to $\mathrm{Pt}+\mathrm{Ge}=100 \%$ ). High-resolution Ge map of GePt black obtained by Energy Filtered TEM (EFTEM) showed Ge scattered in the near-surface regions. Both catalysts were tested in hexane $(\mathrm{nH})$ transformation reactions between 543 and $603 \mathrm{~K}$ and 60 to $480 \mathrm{Torr}_{2} \mathrm{H}_{2}$ pressure (with 10 Torr $\mathrm{nH}$ ), and compared with the parent Pt catalysts. $\mathrm{GePt} / \mathrm{SiO}_{2}$ catalyst was also tested with methylcyclopentane (MCP). Adding $\mathrm{Ge}$ to $\mathrm{Pt} / \mathrm{SiO}_{2}$ lowered the activity; the opposite effect was observed with GePt black. The selectivities of saturated products on bimetallic catalysts decreased, while those of hydrogenolysis products, benzene and hexenes increased in $\mathrm{nH}$ transformations over supported catalyst. The reverse effects were observed over the black samples where addition of Ge prevented accumulation of adventitious carbon. Ring opening was the main reaction with $\mathrm{MCP}$, together with some fragments, benzene and unsaturated hydrocarbons. Ring opening of MCP became more selective with decreasing temperature and increasing hydrogen pressure. Ge on GePt black blocked contiguous Pt sites favoring the formation of coke precursors. The different catalytic behavior of $\mathrm{GePt} / \mathrm{SiO}_{2}$ indicated somewhat different $\mathrm{Pt}-\mathrm{Ge}$ interaction(s).
\end{abstract}

Keywords: GePt, bimetallic catalyst, underpotential deposition, XPS, EFTEM, hexane isomerization, aromatization, methylcyclopentane ring opening

\section{Introduction}

Platinum is the typical active metal component in bifunctional catalysts of naphtha reforming for producing high-octane gasoline [1,2,3]. It is responsible for hydrogenation- dehydrogenation reactions [4] but also for producing $\mathrm{C}_{5}$ and $\mathrm{C}_{6}$ cyclic products in hydrogen excess as well as the opening of the $\mathrm{C}_{5}$ rings [5]. Useful reactions are accompanied by the formation of polymeric carbonaceous deposits ("coke") on contiguous Pt surfaces. Introducing second metals (such as Re, Sn, Ge) would divide the metal surface into smaller islands, preventing thus polymerization of unsaturated intermediates to form a two-dimensional layer of potential coke precursors. At the same time small metallic ensembles required for the production of cyclic compounds as well as isoalkanes [6] were still present. The added second components have, as a rule, low catalytic activity (to this end, $\mathrm{Re}$ is sulfided). The character of the interaction of these second metals with platinum has not been clarified, yet. There is no agreement in the literature 
whether a purely geometric effect (as outlined above) or electronic interactions take place and which of them is the main reason of the beneficial effect of the second metal [6,7,]. The advocates of both views presented experimental results for supporting their theories; for example, Goldwasser et al. [8] attributed the improved catalytic properties of precalcined Pt-Ge/ $/ \mathrm{Al}_{2} \mathrm{O}_{3}$ catalysts merely to geometric effects, whereas Borgna et al. [9] detected an electronic interaction between $\mathrm{Pt}$ and Ge by EXAFS. The oxidation state of Ge [7] and the possible existence of Pt-Ge intermetallic compounds [10] during catalytic reaction have been studied, but these problems still represent a matter of question. Thus, the interaction of the two metals (and the resulting catalytic effect) is a problem influenced by several factors.

In addition to "classical" methods of preparing bimetallic catalysts [6], the methods of "controlled surface reaction" (CSR) is becoming more and more widespread. These include reaction of an organometallic compound with hydrogen chemisorbed on the surface of the first metal [11] as well as underpotential deposition of a second metal on to the surface of the catalytically active component of the monometallic catalyst [12], i.e., Pt in our case.

Our recent paper [13] used organometallic grafting for preparing Pt-Ge/ $/ \mathrm{Al}_{2} \mathrm{O}_{3}$ catalysts with various $\mathrm{Ge}$ content. The amount of Ge added was expressed there in terms of monolayers: e.g., "Ge1/12" means adding $1 / 12 \mathrm{Ge}$ to $\mathrm{Pt}$ while "Ge 1" means 1 monolayer Ge on Pt. A "surface bimetallic system" arose with Ge less than one monolayer whereas a "bulk bimetallic system" started to form with 1 and 2 monolayers of Ge. Catalytic tests with hexane, cyclohexene and benzene indicated a selective deposition of Ge on high-coordination sites, blocking (100) and (111) sites. The latter configuration represents the active centers for aromatization [14]. Samples with low Ge content (Ge $1 / 8$ and $\mathrm{Ge} 1 / 2$ ) were most active in hexane transformation. $\mathrm{Pt}-\mathrm{Ge}$ catalysts produced also saturated hydrocarbons with highest selectivities: mostly methylcyclopentane (MCP) at lower $\mathrm{p}\left(\mathrm{H}_{2}\right)$ and isoalkanes at higher $\mathrm{p}\left(\mathrm{H}_{2}\right)$ values. This agreed with the report by Mariscal et al. [7]: maximum activity and best isomer selectivities in heptane reactions appeared at intermediate Ge concentrations.

The present study deals with two Ge-Pt catalysts prepared with underpotential deposition of Ge [12], like in the case of Pt-Rh catalysts $[15,16]$. These catalysts were characterized by cyclic voltammetry, electron spectroscopy and electron microscopy, as well as test reactions of hexane and methylcyclopentane. All of their "skeletal" reactions can be catalyzed also by the metallic function only [4,17], (even if some reactions are more rapid in the presence of the acidic function). The catalytic reaction itself will also be used to obtain reliable information on the actual state of the surface of the metal catalyst [18]. Supported and unsupported Ge-Pt samples were compared with their monometallic parent catalysts.

\section{Experimental}

\subsection{Catalyst preparation}

The parent unsupported catalyst was Pt black prepared by reduction of $\mathrm{H}_{2} \mathrm{PtCl}_{6}$ with aqueous hydrazine [19] and sintered in $\mathrm{H}_{2}$ at $473 \mathrm{~K}$ [20]. A nonacidic material: $\mathrm{SiO}_{2}$ has been selected for the support of $\mathrm{Pt}$, since the second metal (as Ge oxide) could also interact with the acidic function of the bifunctional reforming catalysts [21]. A well-characterized $3.1 \% \mathrm{Pt} / \mathrm{SiO}_{2}$ (InCat-1 [22]) was used as the parent catalyst. It was prepared by ion exchange using $\left[\mathrm{Pt}\left(\mathrm{NH}_{3}\right)_{4}\right] \mathrm{Cl}_{2}$ at $\mathrm{pH}=10$ [23] and used for comparison as a monometallic $\mathrm{Pt} / \mathrm{SiO}_{2}$ catalyst. The specific surface of the silica support was $300 \mathrm{~m}^{2} \mathrm{~g}^{-1}$ [22,23,24].

The second metal, Ge was deposited on both parent platinum catalysts via the ionization of pre-adsorbed hydrogen (a method based on the underpotential deposition of metals on foreign metal surfaces) $[12,15,16]$. $0.1 \mathrm{~g}$ of Pt catalyst, covered with adsorbed hydrogen was modified with $\mathrm{Ge}$ by exchanging the $1 \mathrm{~mol} \mathrm{~L}^{-1} \mathrm{HCl}$ supporting electrolyte in the reactor with the same volume of deoxygenated $1 \mathrm{M} \mathrm{HCl}$ stock solution saturated with $\mathrm{GeO}_{2}$. The hydrogen adsorbed on Pt parent catalyst reacted with the dissolved $\mathrm{Ge}$, and the electrode potential of the catalyst gradually rose up to about $0.4 \mathrm{~V}$ (with respect to a hydrogen electrode in also $1 \mathrm{M} \mathrm{HCl}$ ), showing that all of the adsorbed hydrogen reacted with Ge. When the reaction of hydrogen (adsorbed on the catalyst) with germanium ions was completed, the catalyst was washed free of germanium ions with deoxygenated $0.2 \mathrm{~mol} \mathrm{dm}^{-3} \mathrm{HCl}$, then with triply distilled water. Finally, the wet catalyst modified with adsorbed $\mathrm{Ge}$ was dried in deoxygenated $\mathrm{N}_{2}$ gas flowing through the reactor while the reactor was warmed with infrared lamp.

\subsection{Catalyst characterization}

\subsubsection{Electrochemical characterization}

As reported for Pt-Rh catalyst, cyclic voltammograms $(\mathrm{CV})$ of $5 \mathrm{mg} \mathrm{Pt}$ and Pt-Ge catalyst were measured at room temperature in a three-compartment electrochemical cell using $0.5 \mathrm{~mol} \mathrm{dm}^{-3} \mathrm{H}_{2} \mathrm{SO}_{4}$ electrolyte. A more detailed description of this procedure can be found in our earlier paper [25]. The upper section of the voltammogram (anodic branch, above the abscissa) corresponds to oxidative processes, whereas the reverse (reductive) processes appear on the cathodic branch, below the abscissa. The electric insulator character of the $\mathrm{SiO}_{2}$ prevented the $\mathrm{CV}$ study of the supported catalyst. 


\subsubsection{XPS}

Surface composition was determined by X-ray Photoelectron Spectroscopy (XPS). A Leybold LHS 12 MCD instrument was used with a $\mathrm{Mg} \mathrm{K}_{\alpha}$ anode for XPS (pass energy, $\mathrm{PE}=48 \mathrm{eV})[19,26,27,28]$. The binding energy (BE) was calibrated to the $\mathrm{Au} 4 \mathrm{f}_{7 / 2}$ line $(\mathrm{BE}=84.0 \mathrm{eV}) . \mathrm{Pt}$ $4 \mathrm{f}$, O $1 \mathrm{~s}, \mathrm{C} 1 \mathrm{~s}$ and $\mathrm{Ge} 3 \mathrm{p}_{3 / 2}$ lines were monitored. Atomic compositions were determined using the SciPlot spectrum evaluation program (@M. Wesemann, Berlin) and literature sensitivity factors [29]. The samples were treated in the preparation chamber with $\mathrm{H}_{2}$ and transferred to the spectrometer chamber without contacting it with air.

\subsubsection{Transmission electron microscopy}

Transmission electron microscopy was used to estimate the particle shape and provide information on their composition. The catalyst sample was ground in an agate mortar, then dispersed in ethanol and dropped onto holey carbon grid. For conventional TEM studies a Philips CM20 electron microscope was used, at $200 \mathrm{kV}$ accelerating voltage. This microscope was capable of carrying out Energy Dispersive X-ray Spectrometric (EDS) analysis on thin specimens with the attached X-ray detector. A $300 \mathrm{kV}$ electron microscope of the type JEOL 3010 with a resolving power of $0.17 \mathrm{~nm}$ and supplemented with a GATAN Tridiem energy post-column energy filter was also applied for high-resolution imaging. This equipment is suitable for acquiring images using electrons of specific energy loss (Energy Filtered TEM, EFTEM) creating thus so-called elemental maps (with a resolution of a few $\mathrm{nm}$ ). For elemental mapping of germanium the Ge-L2,3 edge was used with the 3 energy windows (each of $60 \mathrm{eV}$ slit width), centered at $1247 \mathrm{eV}$ (post-edge), $1117 \mathrm{eV}$ (pre-edge1) and $1177 \mathrm{eV}$ (pre-edge2), respectively.

\subsubsection{Catalytic test reactions}

The catalytic experiments were carried out in a closed-loop glass reactor. A CP 9001 gas chromatograph with a $50 \mathrm{~m}$ CP-Sil 5CB capillary column and FID detector was attached to the system [30]. Batches of 9.2 and $9.7 \mathrm{mg}$ of silica supported and 16.5, $20 \mathrm{mg}$ of unsupported GePt and Pt catalysts, respectively, were placed in the reactor. $\mathbf{G e P t} / \mathrm{SiO}_{2}$ catalyst was tested in hexane $(\mathrm{nH})$ transformation and methylcyclopentane (MCP) ring-opening reactions, while GePt black was tested only with hexane. Standard $\mathrm{nH}$ and MCP pressures of 10 Torr $(1$ Torr $=0.133$ $\mathrm{kPa}$ ) were used while the hydrogen pressures varied between 60 and 480 Torr. The reaction temperatures ranged from 513 to $603 \mathrm{~K}$ in MCP reactions. The temperature range in hexane transformation was 543 to $603 \mathrm{~K}$. Samples were taken after $5 \mathrm{~min}$. Each run was followed by regeneration with $\mathrm{O}_{2}$ (50 Torr, $2 \mathrm{~min}$ ) and $\mathrm{H}_{2}$ (150 Torr, $3 \mathrm{~min}$ ) at the temperature of the preceding run. The catalytic activity

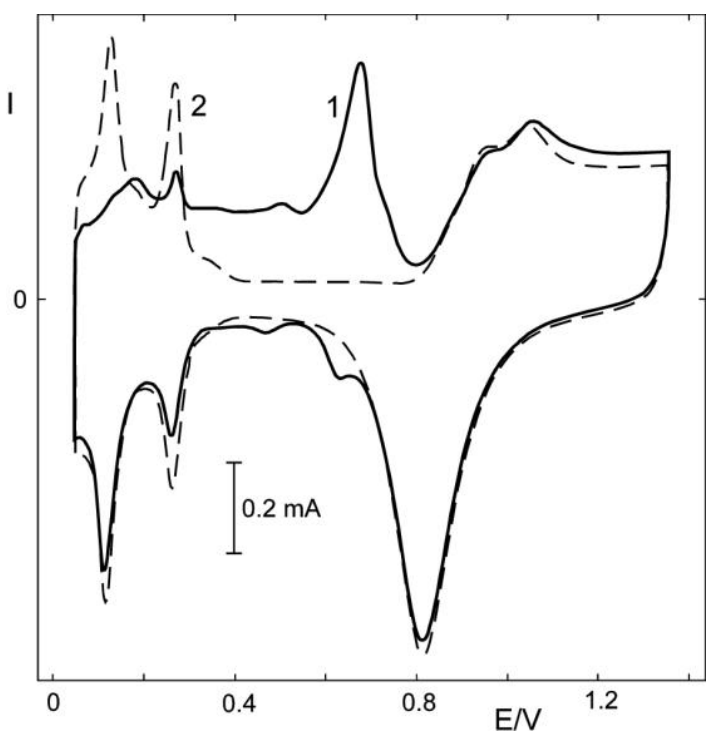

Fig. 1: Cyclic voltammogram of the GePt catalyst (1), and the bare $\mathbf{P t}$ (2) after dissolution of germanium. Sweep rate: $2 \mathrm{mV} \mathrm{s}^{-1}$

was expressed as turnover frequency (TOF, $\mathrm{h}^{-1}$ ) using dispersion data published earlier for Pt black [31]. The dispersion values of supported $\mathbf{P t}$ and $\mathbf{G e P t}$ catalysts were measured by $\mathrm{H}_{2}$ adsorption at room temperature $(298 \mathrm{~K})$ : $52 \%$ for $\mathrm{Pt} / \mathrm{SiO}_{2}$ and $47 \%$ for $\mathrm{GePt} / \mathrm{SiO}_{2}$.

\section{Results}

\subsection{Catalyst characterization}

\subsubsection{Electrochemical characterization}

Figure 1 (curve 1) shows the cyclic voltammogram of the black GePt catalyst. Curve 2 represents the bare platinum surface, which was obtained after dissolution of germanium by 5 potential cycles between 50 and $1350 \mathrm{mV}$. Similar voltammograms were measured during electrochemical investigation of germanium ad-atoms on polycrystalline [32] and on some single crystal platinum electrodes [33,34]. Peaks between 50 and $300 \mathrm{mV}$ correspond to the ionization (anodic side, above the abscissa) or deposition (cathodic side, below the abscissa) of adsorbed hydrogen. Peaks (or waves and humps) above $300 \mathrm{mV}$ potential in the anodic side of the voltammogram (1) can be assigned to the oxidation and to the oxidative desorption of germanium.

Fig. 1 shows that hydrogen adsorption is suppressed by the germanium adatoms. The surface coverage of the $\mathrm{Pt}$ catalyst by Ge can be estimated from the decrease of hydrogen adsorption capacity. Comparing the two voltammograms, about $40-45 \%$ of the Pt surface seems to be blocked by the germanium. If we suppose that site requirement of an adsorbed $\mathrm{Ge}$ atom corresponds to two hydrogen adsorption sites - as was reported in the case of polycrystalline Pt 
[32] and Pd [35] - the Ge:Pt atomic ratio on the surface can be about 1:5.

\subsubsection{XPS}

Photoelectron spectra of the unsupported GePt catalyst were measured in three states: "as is", after $\mathrm{H}_{2}$ treatments: at $300 \mathrm{~K}$ and at $473 \mathrm{~K}$. The atomic compositions are summarized in Table 1. The Ge coverage of ca. $40 \%$ observed by cyclic voltammetry seems to be valid in the catalyst contacting with an aqueous electrolyte solution. This value is valid for the whole information depth (of a few atoms). That is the reason why $\mathrm{CV}$ - that method scanning just the outmost surface layer - detected more Ge. The filtered and dried Pt-Ge shows ca. $96 \% \mathrm{Pt}$ and $4 \% \mathrm{Ge}$ (when normalized to $\mathrm{Pt}+\mathrm{Ge}=100 \%$ ). The "as received" catalyst contained conspicuously low amounts of "adventitious carbon"; thus the electrochemical procedure must have removed rather much carbon. The residual $\mathrm{C}$ was mostly in graphitic state, as reported for the cleanest $\mathrm{Pt}$ black [19]. Hydrogen treatment increased the amount of C in the information depth, in agreement with earlier studies: $\mathrm{H}$ penetrating into subsurface positions of $\mathrm{Pt}$ causes structural rearrangement and "pushes" carbon on to the surface $[28,36]$. Decomposing the C 1s peak showed the same components as reported also for Pt black [28]; most carbon was present as graphene or graphite $(\sim 284.2-\sim 284.6 \mathrm{eV})$ with small amounts of individual $\mathrm{C}$ atoms (BE $\sim 283.8 \mathrm{eV}$ ) and aliphatic polymer $\left(\mathrm{C}_{\mathrm{x}} \mathrm{H}_{\mathrm{y}}, \mathrm{BE} \sim 285.6 \mathrm{eV}\right)$. Oxidized $\mathrm{C}$ (BE > $286 \mathrm{eV}$; typically a minor component [36]) was absent. The shape of $\mathrm{C} 1 \mathrm{~s}$ lines was similar after each treatment, i.e., the ratio of the above-mentioned components did not change noticeably.

Figure $2 \mathrm{a}$ shows the Ge $3 \mathrm{p}_{3 / 2}$ lines. Mostly Ge salt (presumably chloride) was detected in the untreated catalyst. $\mathrm{H}_{2}$ reduced most $\mathrm{Ge}$ even at $300 \mathrm{~K}$. $\mathrm{GeO}_{2}$ also appeared, presumably as a result of reaction of $\mathrm{Ge}$ and oxygen chemisorbed over Pt during storage in air [19]. The $\mathrm{Pt} 4 \mathrm{f}$ peaks in the "as is" state and after $\mathrm{H}_{2}$ treatments appeared at the same binding energy, corresponding to $\mathrm{Pt}^{0}$ (Figure $2 \mathrm{~b}$ ), indicating a clean metallic state with no Pt-O interaction, not even with "chemisorbed oxygen" $(\Delta \mathrm{E} \sim 0.8$ $\mathrm{eV}$ [19]), unlike to what was reported for PtRh [15]).

The insulator character of supported catalyst caused considerable binding energy shift and peak broadening in the XPS peaks of the active components present in small concentrations, as observed with EUROPT-1 (6 \% Pt) [37]. Still lower and uncertain signals could be expected with our $3 \% \mathrm{Pt}$, (Ge may even be around the detection limit - see below, Section 3.1.3.), no XPS measurement was attempted with this sample.

\subsubsection{Transmission electron microscopy}

The left-hand panel of Figure 3 shows transmission electron microscopic (TEM) image of a selected area of
Table 1: Comparison of the surface composition of GePt catalyst measured by XPS in the "as is" state and after hydrogen treatments at 300 and $473 \mathrm{~K}$.

\begin{tabular}{lcccc}
\hline & \multicolumn{4}{c}{ GePt surface composition (\%) } \\
\cline { 2 - 5 } Treatments & Pt 4f & Ge 2p3/2 & C 1s & O 1s \\
\hline GePt "as is" & 81.8 & 3.3 & 4.4 & 10.5 \\
$\mathrm{H}_{2}(300 \mathrm{~K})$ & 72.5 & 2.3 & 16.8 & 8.4 \\
$\mathrm{H}_{2}(473 \mathrm{~K})$ & 76.9 & 2.4 & 15.0 & 5.7 \\
\hline
\end{tabular}

untreated GePt black taken with elastically scattered electrons (zero loss image). On this micrograph, an aggregate of individual crystallites with diameters up to $\sim 50 \mathrm{~nm}[20]$ can be observed. The panels on the right-hand side present Pt-map (Fig 3a) and Ge map (Fig 3b), respectively, obtained by EFTEM of the same area. Not surprisingly, the Pt map shows everywhere the predominance of the main component: Pt. The Ge elemental map represents a quantity of Ge hardly exceeding (or below) the detection limit. However, the image might best be interpreted as a very thin Ge layer partly covering the free surface of the Pt grains. This is supported by the enhanced Ge signal at some edges of the Pt particles in tangential view through the geometrical effect of a thin surface coating [26]. Similar thin $\mathrm{Ge}$ islands may exist on other faces of Pt grains but they remain invisible due to the low signal to noise ratio. The conclusion is the Ge covers the surface of $\mathrm{Pt}$ grains more or less unevenly.

The TEM picture of $\mathbf{G e P t} / \mathbf{S i O}_{2}$ was very similar to that of $\mathrm{PtRh} / \mathrm{SiO}_{2}$ (using the same InCat-1 as parent catalyst) published earlier [16]. EM of the present sample showed no morphological difference in the metallic particles. The small amount of $\mathrm{Ge}$ on this supported catalyst was below the sensitivity limit of the EFTEM.

\subsubsection{Catalytic tests}

\subsubsection{GePt/SiO ${ }_{2}$ in the catalytic reaction of hexane}

Figure 4 illustrates how the turnover frequencies for hexane conversion changed on both catalysts as a function of temperature and hydrogen pressure. The turnover frequencies on the bimetallic GePt samples were much lower. The presence of Ge decreases the continuous Pt surface and decreases the number of active sites. This correlates well with the dispersion determined by hydrogen chemisorption, its value decreasing from $52 \%$ to $47 \%$. This means that adding a second metal to Pt may also exert a hampering effect in the overall activity. Thus, the total number of sites active in hydrogen chemisorption decreases, but, at the same time, sites possessing particular catalytic properties are created. This will alter the product distribution (Table $2)$. Isomers, hydrogenolysis products $\left(<\mathrm{C}_{6}\right)$ and $\mathrm{MCP}$ were formed from hexane on each catalyst and also benzene and unsaturated hydrocarbons (mainly 1-hexene and cis-2hexene) were observed. Isomerization and $\mathrm{C}_{5}$-cyclization were the main reactions on both catalysts. Selectivity of 

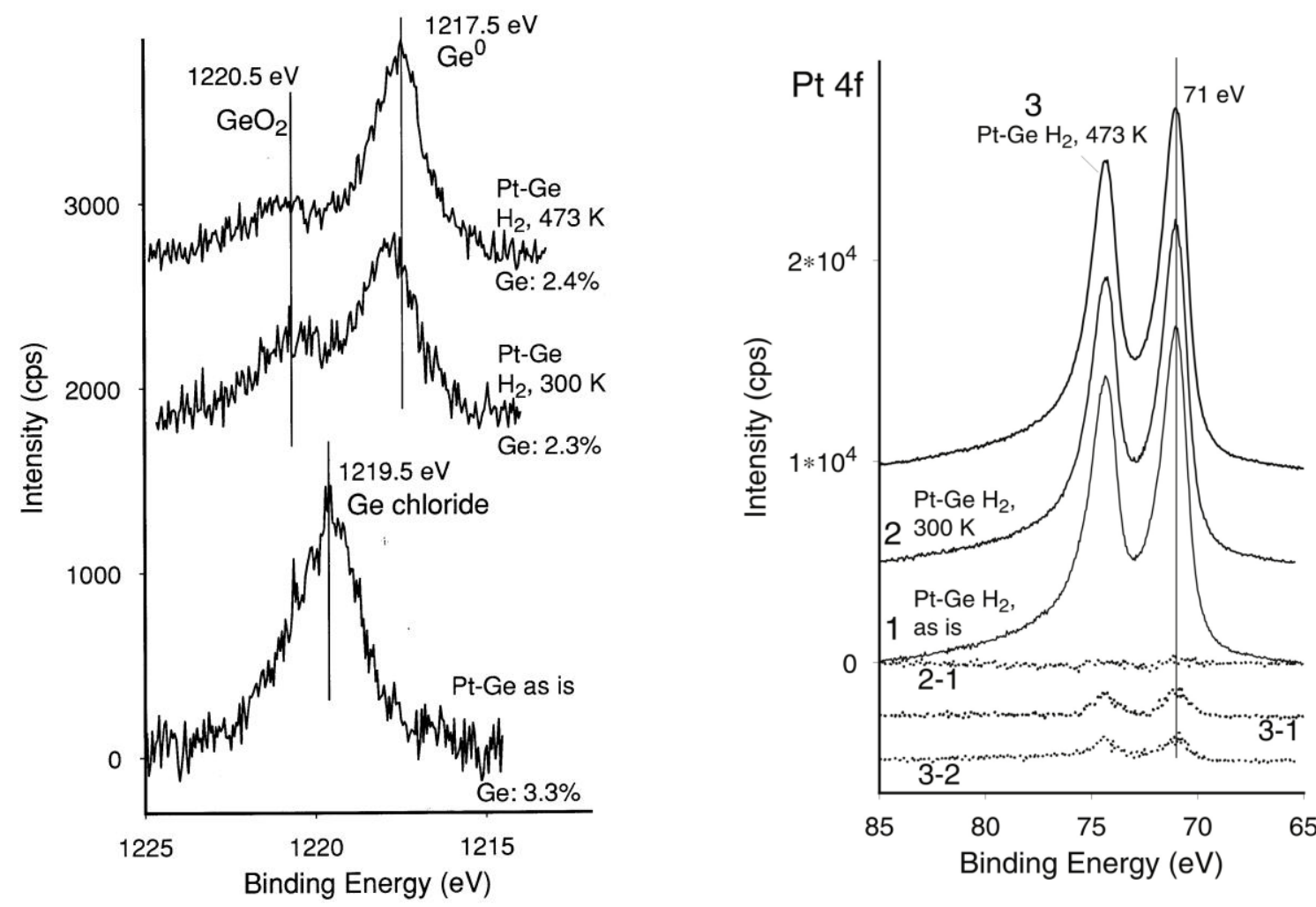

Fig. 2a: Ge 2p 3/2 XP spectra for GePt black catalyst after different treatments. Fig. 2b: Pt 4f XP spectra for GePt black catalyst after different treatments and corresponding difference spectra.
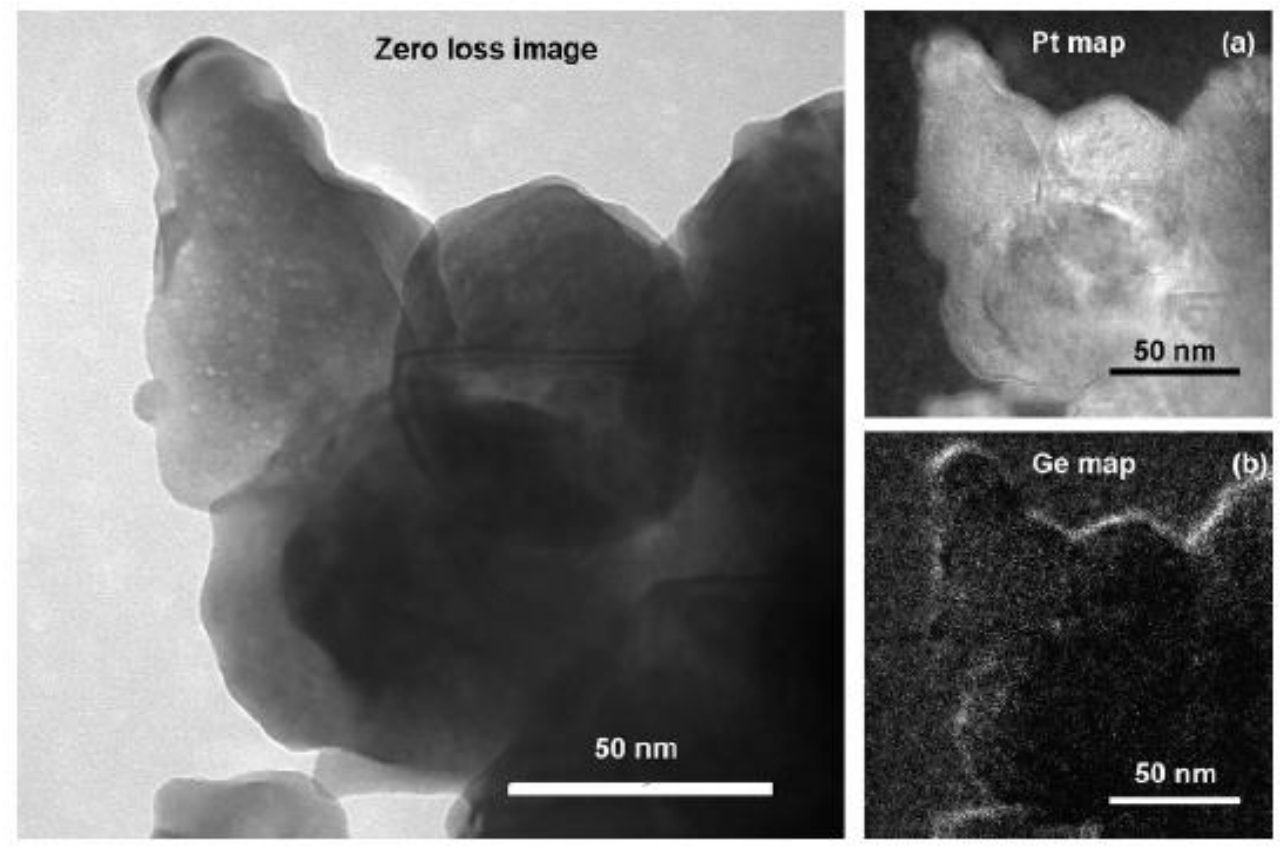

Fig. 3: HRTEM image of GePt black catalyst. (a) Pt map and (b) Ge map of the same area (bright streaks) taken from EELS measurement.

saturated products decreased, while the selectivities of hydrogenolysis and unsaturated products increased over GePt catalyst. Similar selectivity changes could be observed as a function of hydrogen pressure. The formation of saturated products (MCP and isomers) was suppressed and the over- all yield of unsaturated products increased under lower values of hydrogen pressure (Fig. 5). 

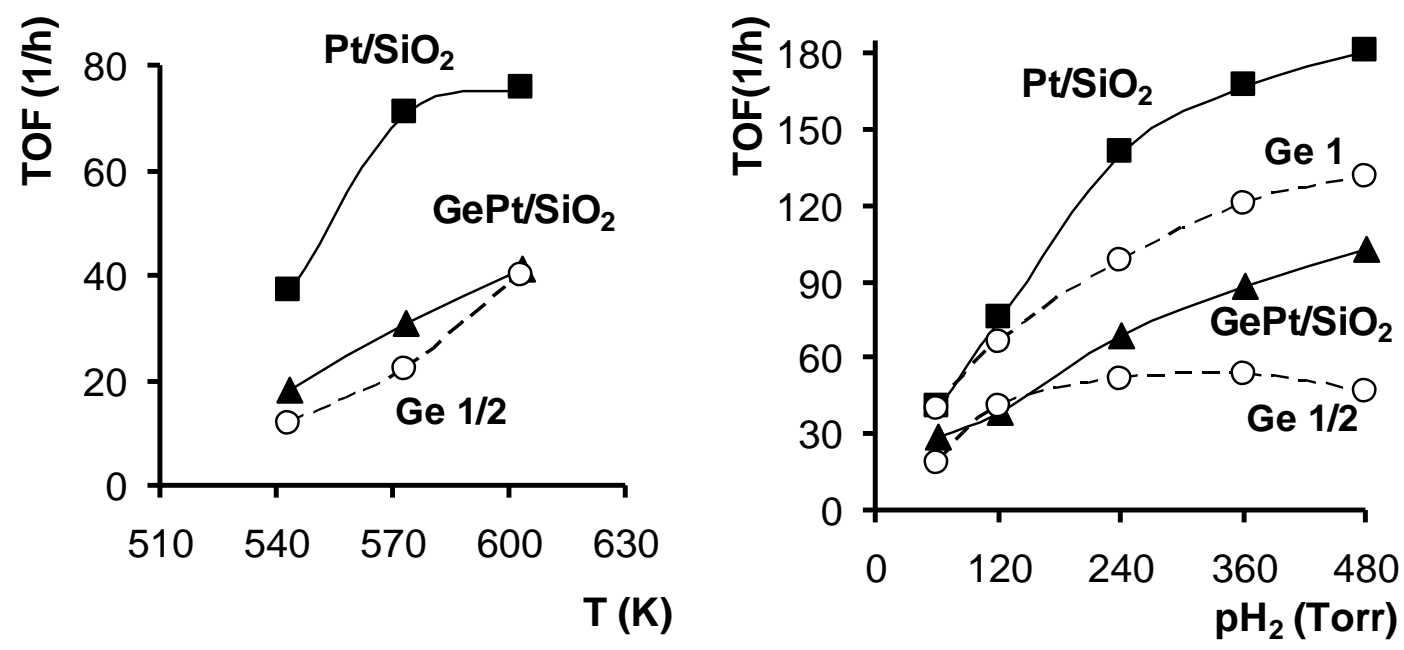

Fig. 4: Turnover frequencies for the conversion of hexane on $\mathbf{a}-\mathbf{P t} / \mathbf{S i O}_{2}$ and $\boldsymbol{\Delta}-\mathbf{G e P t} / \mathbf{S i O} \mathbf{O}_{2}$ as a function of (a) temperature at $\mathrm{p}(\mathrm{MCP}): \mathrm{p}\left(\mathrm{H}_{2}\right)=10: 120$ Torr, $\mathrm{t}=5 \mathrm{~min}$, (b) hydrogen pressure at $\mathrm{T}=603 \mathrm{~K}$. $\circ-\mathrm{Ge} 1 / 2$ and Ge 1 data taken from Ref [13].
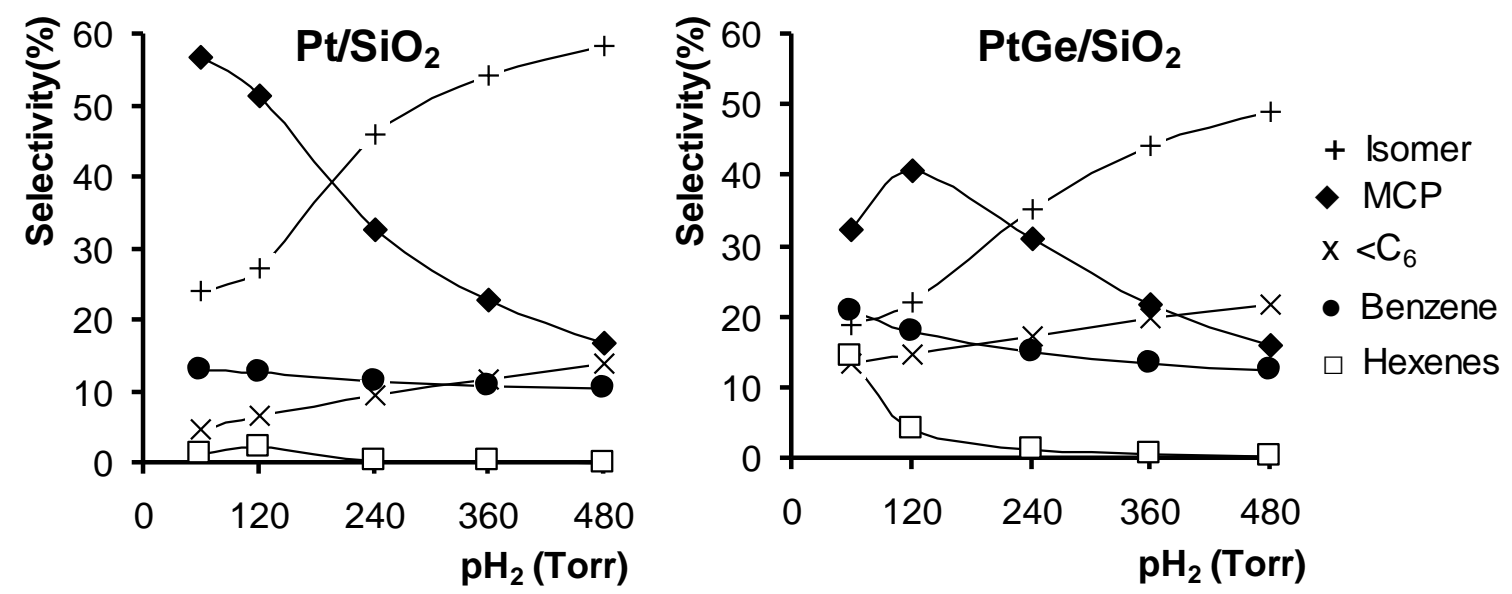

Fig. 5: Comparison of selectivity pattern of hexane reactions on $\mathbf{P t} / \mathrm{SiO}_{2}$ and $\mathbf{G e P t} / \mathbf{S i O} \mathbf{O}_{2}$ at $\mathrm{T}=603 \mathrm{~K}$ as a function of hydrogen pressure.

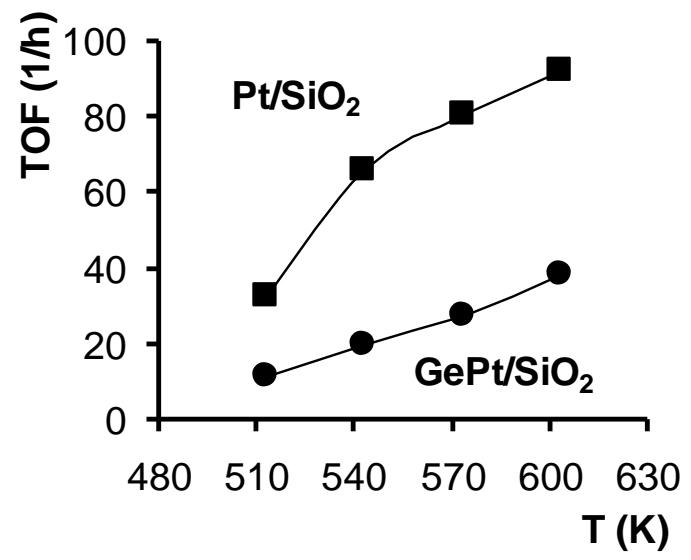

Fig. 6: Conversion of MCP on $\mathbf{- ~} \mathbf{P t} / \mathrm{SiO}_{2}$ and $\bullet-\mathbf{G e P t} / \mathrm{SiO}_{2}$ as a function of temperature $\left(\mathrm{p}(\mathrm{MCP}): \mathrm{p}\left(\mathrm{H}_{2}\right)=10: 120\right.$ Torr, $\mathrm{t}=5 \mathrm{~min}$ )
3.1.4.2 Catalytic reactions of methylcyclopentane on $\mathrm{GePt} / \mathrm{SiO}_{2}$

Ring opening and hydrogenolysis products $\left(<\mathrm{C}_{6}\right)$ were formed from MCP on both catalysts and also unsaturated products were observed. Ring opening took place in three positions producing 2-methylpentane (2MP), 3methylpentane (3MP) and hexane $(\mathrm{nH})$, in proportions different from random ring opening [38]. In addition, $\mathrm{Pt} / \mathrm{SiO}_{2}$ and $\mathrm{Ge}$ modified $\mathrm{Pt} / \mathrm{SiO}_{2}$ produced also benzene and unsaturated products (mainly hexenes). Figure 6 illustrates how the turnover frequencies for MCP conversion changed on both catalysts as a function of temperature. The activity increased with the reaction temperature, but the turnover frequencies on the bimetallic GePt samples were lower in this reaction, too. Figure 7 shows selectivity values as a function of the temperature. In this reaction lower 

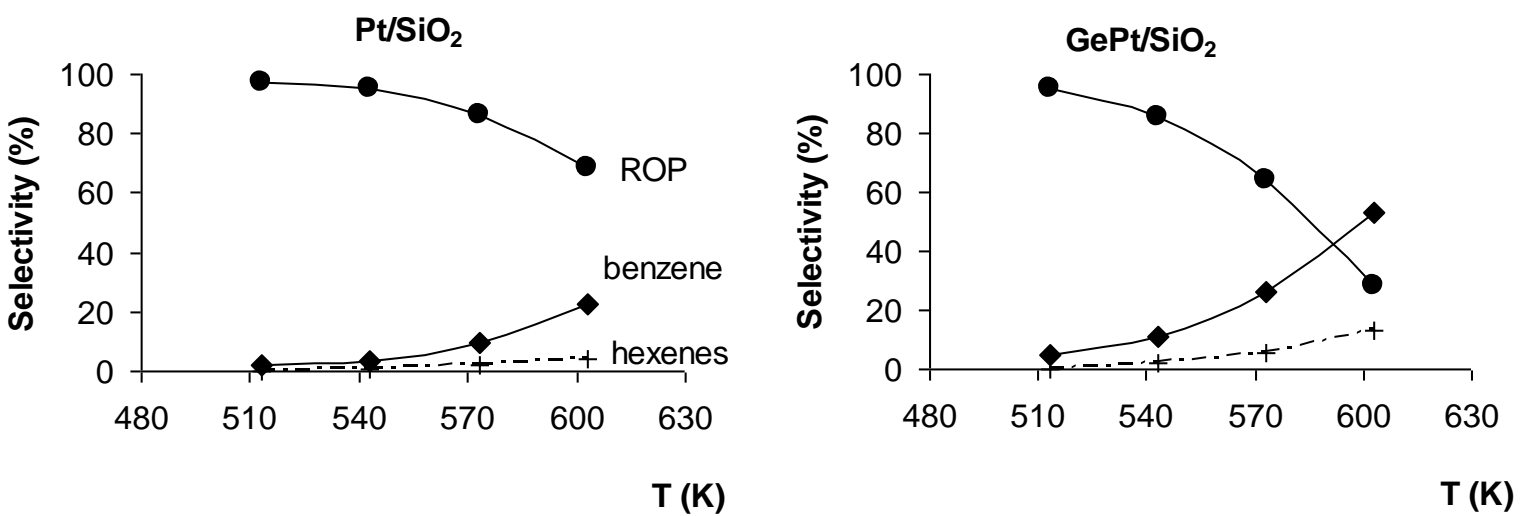

Fig. 7: Selectivity pattern of MCP conversion over $\mathbf{P t} / \mathbf{S i O}_{2}$ and $\mathbf{G e P t} / \mathrm{SiO}_{2}$ as a function of temperature at $\mathrm{p}(\mathrm{MCP}): \mathrm{p}\left(\mathrm{H}_{2}\right)=10: 120$ Torr.

Table 2: Product selectivities of hexane reactions over $\mathrm{SiO}_{2}$ supported $\mathbf{P t}$ and $\mathbf{G e P t}$ catalysts as a function of temperature [p(nH):p( $\left.\mathrm{H}_{2}\right)=10: 120$ Torr]

\begin{tabular}{|c|c|c|c|c|c|c|}
\hline \multirow[b]{3}{*}{ Temperature (K) } & \multicolumn{6}{|c|}{ Selectivity (\$) } \\
\hline & \multicolumn{3}{|l|}{ Pt } & \multicolumn{3}{|l|}{ GePt } \\
\hline & $\overline{543}$ & 573 & 603 & $\overline{543}$ & 573 & 603 \\
\hline$<C_{6}$ & 7.1 & 9.8 & 7.2 & 20.8 & 16.4 & 16.4 \\
\hline lsomers & 36.6 & 25.3 & 25.7 & 35.2 & 2.1 & 20.3 \\
\hline Hoxenes & - & 0.8 & 1.9 & - & 1.5 & 4.1 \\
\hline MCP & 49.7 & 55.6 & 53.2 & 35.3 & 43.4 & 43.4 \\
\hline Benzene & 6.6 & 8.5 & 12 & 8.7 & 11.6 & 15.8 \\
\hline
\end{tabular}

Table 3: Ratio of ring opening products of MCP on supported catalysts as a function of temperature (at $\mathrm{p}(\mathrm{MCP}): \mathrm{p}\left(\mathrm{H}_{2}\right)=10: 120$ Torr) and hydrogen pressure. Selected typical values are shown.

\begin{tabular}{|c|c|c|c|c|c|c|}
\hline \multirow[b]{3}{*}{ Statistical Ro } & \multicolumn{3}{|l|}{$\mathrm{Pt} / \mathrm{SiO}_{2}$} & \multicolumn{3}{|l|}{$\mathrm{GePt} / \mathrm{SiO}_{2}$} \\
\hline & $2 \mathrm{MP} / 3 \mathrm{MP}$ & $2 \mathrm{MP} / \mathrm{nH}$ & $3 \mathrm{MP} / \mathrm{nH}$ & $2 \mathrm{MP} / 3 \mathrm{MP}$ & $2 \mathrm{MP} / \mathrm{nH}$ & $3 \mathrm{MP} / \mathrm{nH}$ \\
\hline & 2 & 1 & & & & \\
\hline \multicolumn{7}{|c|}{ Temperature (K) } \\
\hline 513 & 2.7 & 2.0 & 0.7 & 2.8 & 5.0 & 1.8 \\
\hline 543 & 2.6 & 1.7 & 0.7 & 2.4 & 3.0 & 1.3 \\
\hline 573 & 2.2 & 1.4 & 0.6 & 2.0 & 2.4 & 1.1 \\
\hline 603 & 1.9 & 1.3 & 0.7 & 1.7 & 1.5 & 0.9 \\
\hline \multicolumn{7}{|c|}{$\mathrm{H}_{2}$ pressure (Torr) $T=603 \mathrm{~K}$} \\
\hline 60 & 1.7 & 1.3 & 0.7 & 1.7 & 1.2 & 0.7 \\
\hline 120 & 1.9 & 1.3 & 0.7 & 1.7 & 1.5 & 0.9 \\
\hline 240 & 2.2 & 1.3 & 0.6 & 1.9 & 2.3 & 1.2 \\
\hline 360 & 2.3 & 1.3 & 0.6 & 2.1 & 2.7 & 1.3 \\
\hline 480 & 2.3 & 1.3 & 0.6 & 2.3 & 3.0 & 1.3 \\
\hline \multicolumn{7}{|c|}{$\mathrm{H}_{2}$ pressure $($ Torn) $T=573 \mathrm{~K}$} \\
\hline 60 & 1.9 & 1.3 & 0.7 & 1.8 & 1.6 & 0.9 \\
\hline 120 & 2.2 & 1.4 & 0.6 & 2.0 & 2.4 & 1.1 \\
\hline 240 & 2.6 & 1.4 & 0.6 & 2.3 & 3.8 & 1.7 \\
\hline 360 & 2.7 & 1.4 & 0.5 & 2.6 & 4.7 & 1.8 \\
\hline 480 & 2.8 & 1.3 & 0.5 & 2.8 & 5.0 & 1.8 \\
\hline
\end{tabular}

amounts of hydrogenolysis products were formed. The selectivity of $\left\langle\mathrm{C}_{6}\right.$ changed between $0.5-4.5 \%$, increasing with the temperature. Ring opening was the main reaction on both catalysts. Over GePt catalyst the selectivity of saturated products decreased, while the selectivities of benzene and hexenes increased with increasing temperature like in hexane reactions. At $603 \mathrm{~K}$ the selectivity of hexenes was three times higher on GePt than over Pt (Fig. 7). As for the position of ring opening, Gault and co-workers have postulated a "selective" and "nonselective" pathway of the $\mathrm{C}_{5}$ ring opening [39]. The latter would produce a statistical distribution of 2MP, 3MP and $\mathrm{nH}$, while much less (or even zero) $\mathrm{nH}$ would be produced in the "selective" ring opening. Table 3 shows the selectivity of ring opening products in MCP transformation on Pt and GePt. The parent $\mathbf{P t}$ catalyst was less selective in ring opening reactions and the selectivity was hardly affected by the temperature. The deviation from random ring opening was somewhat larger at $573 \mathrm{~K}$ than at $603 \mathrm{~K}$ and at higher $\mathrm{H}_{2}$ pressures. Over bimetallic catalyst the ring opening was rather "selective" at $513 \mathrm{~K}$, while this selective character decreased with increasing temperature and the ring opening became roughly statistical at $603 \mathrm{~K}$, indicating that "adlineation sites" [40] might have been present and active on the $\mathrm{Pt} / \mathrm{SiO}_{2}$ borderline. The selectivities on catalysts were compared as a function of hydrogen pressure at 573 and $603 \mathrm{~K}$. Ring opening selectivities were hardly affected by hydrogen pressure over parent $\mathbf{P t}$ catalyst (all ratios were close to statistical), while on GePt the ring opening became remarkably selective with increasing $\mathrm{p}\left(\mathrm{H}_{2}\right)$. The ratio 2MP/3MP was very stable while the MP/nH ratios (chracteristic of the "selective" ring opening showed somewhat larger scattering)

\subsubsection{GePt black in the catalytic reaction of hexane}

Figure 8 shows how the turnover frequencies for hexane conversion changed on both unsupported catalysts as a function of temperature and hydrogen pressure. The turnover frequencies on the bimetallic GePt samples were much higher, meaning that the presence of Ge increased the catalytic activity. This is in agreement with the purity of GePt (Table 1; the $\mathrm{O}$ component must have been removed by $\mathrm{H}_{2}$ in the reaction mixture. Isomerization and $\mathrm{C}_{5^{-}}$ cyclization were the main reactions on both catalysts (Table 4), except on Pt at $603 \mathrm{~K}$, where hydrogenolysis had highest selectivity. The selectivity of saturated products increased, while those of hydrogenolysis and unsaturated products decreased over GePt catalyst. Similar tendencies of selectivity changes could be observed as a function of hydrogen pressure. The formation of saturated products 

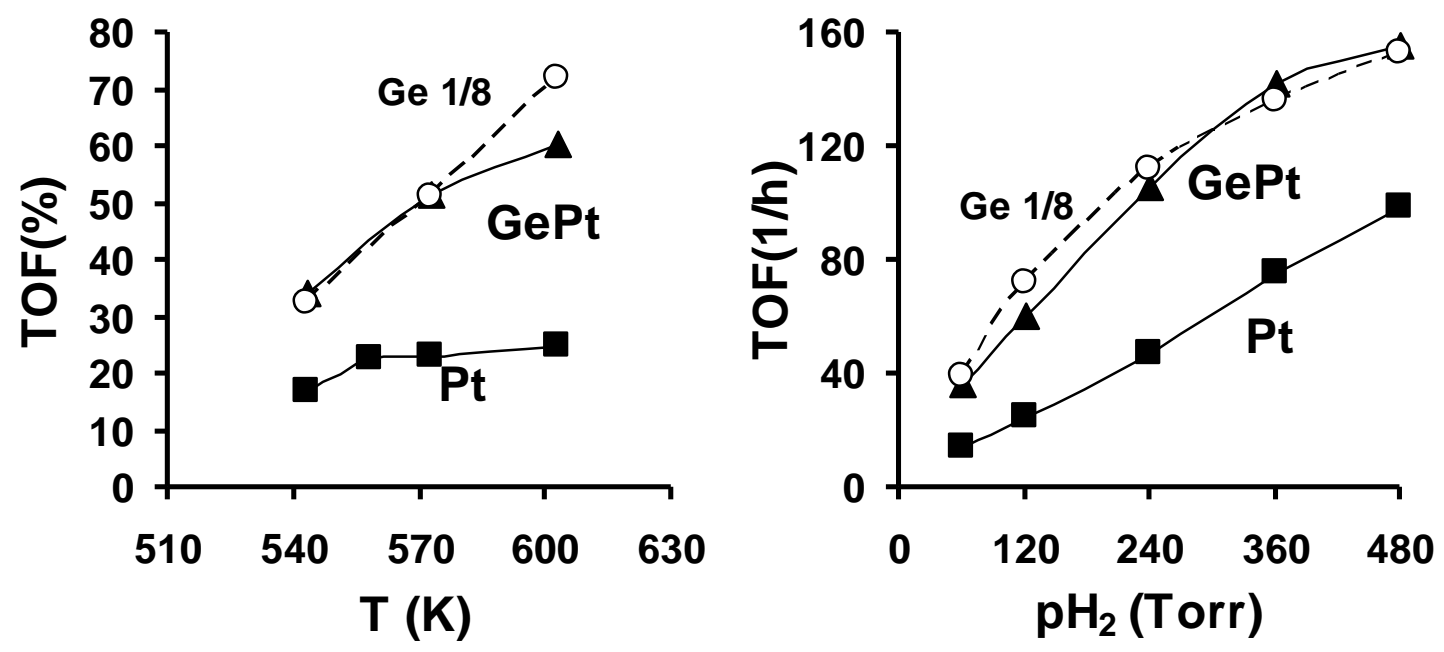

Fig. 8: Turnover frequencies for the conversion of hexane on - Pt and $\boldsymbol{\Delta}$ - GePt black as a function of (a) temperature at $\mathrm{p}(\mathrm{MCP}): \mathrm{p}\left(\mathrm{H}_{2}\right)=10: 120$ Torr, $\mathrm{t}=5 \mathrm{~min},(\mathrm{~b})$ hydrogen pressure at $\mathrm{T}=603 \mathrm{~K} . \circ-\mathrm{Ge}$ 1/8 data taken from Ref [13].
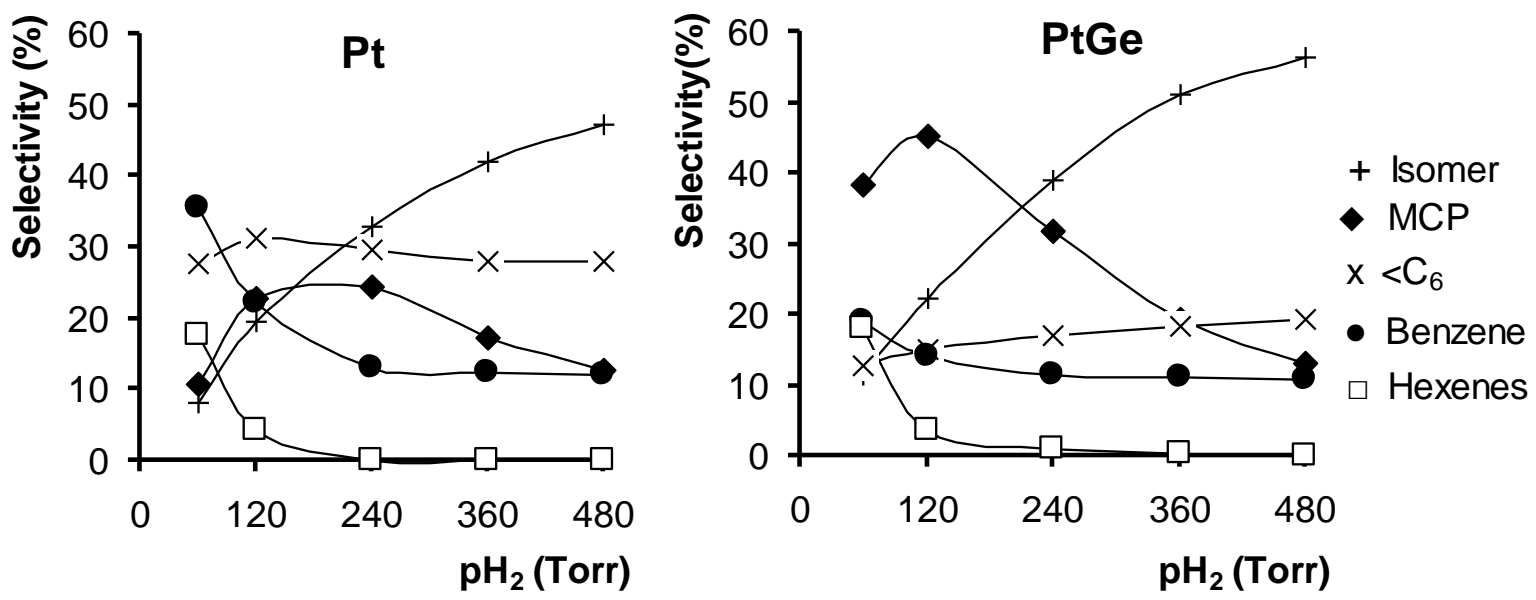

Fig. 9: Selectivity pattern of hexane reactions on $\mathbf{P t}$ and $\mathbf{G e P t}$ black at $\mathrm{T}=603 \mathrm{~K}$ as a function of hydrogen pressure.

(MCP and isomers) increased and the overall yield of unsaturated products decreased (Fig. 9).

\section{Discussion}

Our previous study [13] revealed that small amounts of Ge (Ge 1/12 and Ge1/8) increased the catalytic activity of $\mathrm{Pt}$ and also the selectivities to saturated products (skeletal isomers and MCP) from hexane. The reason was the selective deposition of small amounts of germanium to platinum into positions where reactions requiring multiple sites (fragmentation [41] and aromatization [14]) would occur. In the Ge1/2 sample, much higher fraction of the surface was covered with inactive $\mathrm{Ge}$, rendering this sample the least active of the series. Samples Ge1 and Ge2 contained a high fraction of $\mathrm{Ge}$ in deeper layers, forming "bulk bimetallic" catalysts which again contained more active surface Pt sites [13], but not necessarily with the same selectivities.

Just one bimetallic GePt sample was prepared using the method in the present study; the Ge:Pt ratio was constant. The overall activity of $\mathbf{G e P t} / \mathbf{S i O}_{\mathbf{2}}$ was lower than that of its parent catalyst (Figure 3). The temperature dependence of the activity of our bimetallic sample was closer to that of $\mathbf{G e 1 / 2}$ (on $\mathrm{Al}_{2} \mathrm{O}_{3}$ support), indicating that the electrochemical deposition introduced sufficient germanium to transform the small $\mathrm{Pt}$ particles $(3 \pm 0.7 \mathrm{~nm}$ [16]) to a bimetallic system with random Ge deposition along the whole Pt surface. The hydrogen pressure dependence, in turn, was between the results observed with Ge1 and $\mathbf{G e 1 / 2}$, i.e., our $\mathbf{G e P t} / \mathrm{SiO}_{2}$ was better than $\mathbf{G e 1 / 2}$ with randomly deposited Ge on the surface but inferior to Ge1 where bulk Ge-Pt formation started, liberating some surface Pt sites for catalysis. These sites could be successfully activated by more surface hydrogen. The relatively high frag 
Table 4: Product selectivities of hexane reactions over unsupported $\mathbf{P t}$ and $\mathbf{G e P t}$ catalysts as a function of temperature $\left[\mathrm{p}(\mathrm{nH}): \mathrm{p}\left(\mathrm{H}_{2}\right)=10: 120\right.$ Torr]

\begin{tabular}{|c|c|c|c|c|c|c|}
\hline \multirow[b]{3}{*}{ Temperature (K) } & \multicolumn{6}{|c|}{ Selectivity (\$) } \\
\hline & \multicolumn{3}{|l|}{ Pt } & \multicolumn{3}{|l|}{ GePt } \\
\hline & $\overline{543}$ & 573 & 603 & 543 & 573 & 603 \\
\hline$<C_{6}$ & 20.8 & 25.4 & 31.2 & 14.3 & 12.6 & 15.1 \\
\hline Isomers & 40.3 & 31.9 & 19.7 & 44.8 & 30.2 & 22.1 \\
\hline Hewenes & - & 0.4 & 4.2 & - & 1.3 & 3.6 \\
\hline MCP & 26.7 & 29.3 & 22.8 & 28.7 & 44.9 & 45.1 \\
\hline Benzene & 12.2 & 13 & 22.1 & 12.2 & 11 & 14.1 \\
\hline
\end{tabular}

mentation selectivity of $\mathbf{G e P t} / \mathrm{SiO}_{\mathbf{2}}$ (Table 2) and benzene selectivity values were also analogous to earlier results obtained with Ge1/2 [13]. The saturated products formed over $\mathbf{G e P t} / \mathrm{SiO}_{2}$ consisted mainly of MCP (Figure 5) indicating the poorer utilization of higher $\mathrm{H}_{2}$ pressures to create $\mathrm{Pt}-\mathrm{H}$ sites necessary to promote opening of the MCP ring to isomers. The same conclusions could be drawn from using MCP probe molecules (Figure 7). The selectivity to ring opening products decreased more strongly at higher temperatures with $\mathbf{G e P t} / \mathrm{SiO}_{2}$ than with $\mathbf{P t} / \mathrm{SiO}_{2}$. The bimetallic catalyst produced more benzene than $\mathbf{P t} / \mathbf{S i O}_{2}$ whereas the amount of fragments was negligible. This also indicates the presence of smaller, hydrogen-poor active ensembles. Ring opening was not very selective on $\mathbf{P t} / \mathrm{SiO}_{\mathbf{2}}$ (Table 3); lower temperatures and higher hydrogen pressures favouring "selective" ring opening. This situation changed dramatically on $\mathbf{G e P t} / \mathrm{SiO}_{2}$, indicating that adding Ge almost eliminated the role of adlineation sites [40] on the Pt-silica borderline. Another reason for the excess of methylpentanes may be due to the consumption of a fraction of hexane precursors to produce benzene. The fact that no "Pt-Ge borderline effect" arose indicates again the high dispersion of Ge. Since the support was inactive, "Gesupport" interactions did not influence the catalytic properties.

Ge deposition on to the unsupported Pt produced a cyclic voltammogram suggesting ca. $40 \%$ surface Ge that would agree well with the Ge content of Ge1/2. Our GePt black catalyst was, however, better than the parent Pt (Figure 9). Its behaviour (Figure 8) was analogous to the second best bimetallic alumina-supported sample, i.e., Ge1/8 [13]. The selectivities on GePt were close to the values measured on $\mathbf{G e P t} / \mathrm{SiO}_{2}$, both as a function of reaction

\section{References}

[1] G.A. Mills, H. Heinemann, T. H. Milliken, A. G. Oblad, Ind. Eng. Chem., 45 (1953) 134.

[2] G. J. Antos, A. M. Aitani (Eds.) Catalytic Naphtha Reforming $2^{\text {nd }}$ Ed., Marcel Dekker, 2004.

[3] B. H. Davis, Catal. Today, 53 (1999) 443.

[4] Z. Paál in G. J. Antos, A. M. Aitani (Eds.) Catalytic Naphtha Reforming second ed., Marcel Dekker, 2004, p. 35.

[5] J. H. Sinfelt, in G. Ertl, H. Knözinger, J. Weitkamp (eds.) Handbook of Heterogeneous Catalysis, Vol. 4, Verlag Chemie, Weinheim, 1997, p. 1939. temperature (Tables 2 and 4) and $\mathrm{H}_{2}$ pressure (Figures 5 and 9). These values show a marked improvement of GePt as compared to the parent Pt black. Deposition of Ge must have prevented accumulation of adventitious $\mathrm{C}$ in both cases. This may be a new important statement about these bimetallic catalysts containing low amount of additive.

The electrochemical method, in principle cannot deposit more than 1 monolayer on the parent metal. The catalytic results indicate that the resulting amount of germanium was between $1 / 2$ and 1 monolayers on $\mathrm{SiO}_{2}$ supported catalyst. This $\mathrm{Pt} / \mathrm{Ge}$ ratio was far from the optimum on alumina supported catalysts and the results with $\mathbf{G e P t} / \mathrm{SiO}_{2}$ were in agreement with this experience. $\mathrm{Pt}$ black with small specific surface, in turn, improved markedly upon deposition of Ge, covering, obviously continuous $\mathrm{Pt}$ sites favoring deactivation and leaving smaller Pt ensembles active in the desired isomerization- $\mathrm{C}_{5}$-cyclization reactions. Thus, catalytic data indicate low actual surface concentration of Ge. XPS (Table 1) would suggest a $\mathrm{Ge} / \mathrm{Pt}$ ratio even lower than Ge1/12, the majority of Ge being present as $\mathrm{Ge}^{0}$ (Figure 2a). One has to consider that some platinum must be covered by carbon and some of oxygen is also present on Pt, i.e., the comparison with Ge1/8 [13] seems to be realistic. These catalytic results are in agreement with the EFTEM pictures (Figure 3), showing contiguous Pt and scattered Ge signal. One must not forget that atomically dispersed Ge would not be able to produce visible signals above detection limit, i.e., the light spots on the Ge map must correspond to small islands representing only a fraction of the total germanium amount. Even the presence of small amount of Ge prevented the appearance of $\mathrm{Pt}-\mathrm{O}_{\mathrm{ads}}$ observed earlier with Pt black exposed to air [19].

\section{Acknowledgement}

The authors are thankful to Dr. Attila Wootsch for valuable advice during experiments and their evaluation. Financial support of the Max-Planck Institute for XPS measurements in Berlin is gratefully acknowledged.

[6] V. Ponec, G. C. Bond, Catalysis by Metals and Alloys, Stud. Surf. Sci., Catal. Elsevier, Amsterdam, 1995.

[7] R. Mariscal, J. L. Garcia Fierro, J. C. Jori, J. M. Parera, J. M. Grau, Appl. Catal. A General, 327 (2007) 123.

[8] J. Goldwasser, B. Arenas, C. Bolivar, et al. J. Catal. 100 (1986) 75 .

[9] A Borgna, T. F. Garetto, C. R. Apesteguia, B. Moraweck, Appl. Catal. A, $182 \quad$ (1999) 189.

[10] Z. Huang,, J. R. Fryer, C. Park, D. Stirling, G. Webb, J. Catal., 175 (1998) 226. 
[11] J. Margitfalvi, M. Hegedüs, S. Göbölös, E. Kern-Tálas, P. Szedlacsek, S. Szabó, F. Nagy, Proc. $8^{\text {th }}$ International Congress on Catalysis, Berlin, 1984, Verlag Chemie,Weinheim, Vol. 4, p. 903.

[12] S. Szabó, Int. Rev. Phys. Chem., 10 (1991) 207.

[13] A. Wootsch, Z. Paál, N. Győrffy, S. Ello, I. Boghian, J. Leverd, L. Pirault-Roy, J. Catal., 238 (2006) 67.

[14] P. Biloen, J. N. Helle, H. Verbeek, F. M. Dautzenberg, W. M. H. Sachtler, J. Catal., 63 (1980) 112.

[15] Z. Paál, N. N. Győrffy, A. Wootsch, L. Tóth, I. Bakos, S. Szabó, U. Wild, R. Schlögl, J. Catal., 250 (2007) 254.

[16] N. Győrffy, A. Wootsch, S. Szabó, I. Bakos, L. Tóth, Z. Paál, Topics Catal., 46 (2007) 57.

[17] Z. Paál, J. Catal. 105 (1987) 540.

[18] G. C. Bond, Metal-Catalyzed Reactions of Hydrocarbons, Springer, New York, 2005.

[19] Z. Paál, U. Wild, A. Wootsch, J. Find, R. Schlögl, Phys. Chem. Chem. Phys. 3 (2001) 2148.

[20] Z. Paál, H. Zimmer, J. R. Günter, R. Schlögl, M. Muhler, J. Catal. 119 (1989) 146

[21] L. S. Carvalho, C. L. Pieck, M. C. Rangel, N. S. Figoli, J. M. Grau, P. Reyes, J. M.Parera, Appl. Catal 269 (2004) 91.

[22] V. A. Drozdov, B. B. Fenelonov, L. G. Okkel, T. I. Gulyaeva, N. V.Antonicheva, N. S. Sludkina, Appl. Catal. A 172 (1998) 7.

[23] J. L. Margitfalvi, I. Borbáth, E. Tfirst, A. Tompos, Catal. Today, 43 (1998) 29.

[24] J. L. Margitfalvi, I. Borbáth, M. Hegedüs, A. Tompos, Appl. Catal. A, 229 (2002) 35.
[25] A. Wootsch, Z. Paál, S. Szabó, I. Bakos, H. Sauer, U. Wild R. Schlögl, Appl. Catal. A, 309 (2006) 1.

[26] Z. Paál, R. Schlögl, Surf. Interf. Anal., 19 (1992) 524.

[27] Z. Paál, R. Schlögl, G. Ertl, J. Chem. Soc. Faraday Trans., 88 (1992) 1179.

[28] U. Wild, D Teschner, R. Schlögl, Z. Paál, Catal. Lett., 67 (2000) 93.

[29] Practical Surface Analysis ed. D. Briggs, M. P. Seah Wiley, Chichester, 1990, Appendix 6, Vol. 1, p. 635.

[30] D. Teschner, D. Duprez, Z. Paál, J. Mol. Catal. A 19 (2002) 201.

[31] A. Wootsch, Z. Paál, J. Catal. 205 (2002) 86.

[32] N. Furuya, S. Motoo, J. Electroanal. Chem., 99 (1979) 19.

[33] R. Gomez, M.J. Llorca, J.M. Feliu, A. Aldaz, J. Electroanal. Chem., 340 (1992) 349.

[34] P. Rodriguez, E. Herrero, J. Solla-Gullo, F.J. Vidal-Iglesias, A. Aldaz, J.M. Feliu, Electrochimica Acta, 50 (2005) 3111.

[35] I. Bakos, S. Szabó, F. Nagy, J. Electroanal. Chem., 309 (1991) 293

[36] N. M. Rodriguez, P. E. Anderson, A. Wootsch, U. Wild, R. Schlögl, Z. Paál, J. Catal.,197 (2001) 365.

[37] M. Muhler, Z. Paál, R. Schlögl, Appl. Surface Sci., 47 (1991) 281.

[38] F. G. Gault, Adv. Catal. 30 (1981) 1.

[39] G. Maire, G. Plouidy, J. C. Prudhomme, F. G. Gault, J. Catal. 4 (1965) 556.

[40] H. Glassl, K. Hayek, R. Kramer, J. Catal. 68 (1981) 397.

[41] J. H. Sinfelt, Adv. Catal. 23 (1973) 91. 